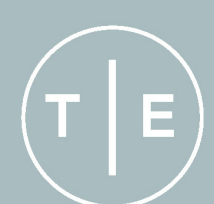

Trabajos de Egiptología

"Those Who Mourn for Re": Mourning and Regeneration in the Book of the Twelve Caverns

Daniel Miguel MÉNDEZ RODRíGUEZ

The Courtyard of TT 209 (Areas C1 and C2). Seasons 2012 to 2014

Miguel Ángel MOLINERO POLO, Cristo Manuel HERNÁNDEZ GÓMEZ.

Algunas reflexiones sobre Uluburun y el intercambio comercial y cultural en el Mediterráneo Oriental

$$
\text { Antonio PÉREZ LARGACHA }
$$

The Framework of the Meeting

Narrative Uses of Stelae in Egyptian Literary Texts José Ramón PÉREZ-ACCINO

Introducción a la investigación arqueológica para estudiantes a través de reconstrucciones virtuales

Sofía PÉREZ-RUIZ, Ainara ACEBO, Pilar RODRÍGUEZ MARíN...

Lucernas decoradas con la imagen de una rana del yacimiento de Oxirrinco, El-Bahnasa, Egipto Esther PONS MELLADO

\section{Trabajos de Egiptología}

\section{Papers on Ancient Egypt}

Estudio preliminar de la cerámica procedente de las excavaciones en la TT 209, Luxor, Egipto

$$
\text { Zulema BARAHONA MENDIETA }
$$

La ocupación macedónica y la Dinastía Lágida. Impacto político, económico y social Francisco BOSCH PUCHE

Reflexiones sobre Meretseguer en la estela EA272 del British Museum

Elisa CASTEL RONDA

Ramesses III as Guarantor of Maat: the Iconographic Evidence at Medinet Habu

$$
\text { Salvador COSTA, Teresa MAGADÁN }
$$

Iconographic Rendering of the Notion of Purification in Two Elements Included in the Vignettes of Chapters 17 and 125 of the Book of the Dead Lucía DÍAZ-IGLESIAS LLANOS

Taboo - bwt?

Paul John FRANDSEN

Flat-Section Hairpins during the Egyptian Predynastic Period? A Proposal of Identification and Typology

Candelaria MARTÍN DEL RÍO ÁLVAREZ

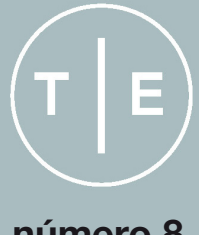

número 8 
Trabajos de Egiptología

Director

Papers on Ancient Egypt

Miguel Ángel Molinero Polo

Universidad de La Laguna, Tenerife, Islas Canarias

Secretaría de edición

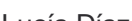

Centro Superior de Investigaciones Cientificas, Madrid

Alba María Villar Gómez

Colaborador de edición I English editorial assistant

Kenneth Griffin

Kenterity Gaino Unido

\section{Consejo de redacción}

Antonio Pérez Largacha

José Ramón Pérez-Accino

Universidad Internacional de la Rioja (UNIR)

José Ramón Perez-Accino
Universidad Complutense de Madrid

\section{Dando agua a los pájaros} Homenaje a Covadonga Sevilla Cueva

Giving water to the birds

An homage to Covadonga Sevilla Cueva

\section{Comité científico}

Marcelo Campagno
CONICET I Universidad de Buenos Aires

Josep Cervelló Autuori

Universitat Autònoma de Barcelona

María José López-Grande

Josep Padró i Parceris

Universitat de Barcelona

M. ${ }^{a}$ Carmen Pérez Die

Museo Arqueológico Nacional, Madrid

José Miguel Serrano Delgado

Evaluadores externos de este número

José Ramón Aja Sánchez | Luis Manuel de Araujo | Juan Antonio Belmonte Avilés | Elena de Gregorio |

Stan Hendryckx | Cristo Manuel Hernández Gómez | Miguel Jaramago Canora | Bill Manley | Alfonso

Martín Flores | Daniel Miguel Méndez Rodriguez | M. ${ }^{2}$ Violeta Pereyra | R. Gareth Roberts | Amelia del

Carmen Rodriguez Rodriguez | José das Candeias Sales | Inmaculada Vivas Sáinz

\section{Fundadores de la Revista}

Miguel Ángel Molinero Pol

José Ramón Pérez-Accino
Covadonga Sevilla Cueva

Editado por I Edited by

Miguel Ángel Molinero Polo | Antonio Pérez Largacha | José Ramón Pérez-Accino

Número 8

2017 







\title{
Reflexiones sobre Meretseguer en la estela EA 272 del British Museum
}

\author{
Elisa CASTEL RONDA
}

En este trabajo se analiza la figura de un ofidio con el cuerpo enroscado en varias vueltas concéntricas que se esculpió en el registro superior derecho de una estela de Deir el-Medina. La pondremos en paralelo con otras representaciones que Reflections on Meretseger in the stela British Museum EA 272

In this work the figure of an ophidium showing its body twisted in several concentric turns is analysed. It was sculpted in the upper right register of a stela from Deir el-Medina. It is compared with other similar representations which could provide

Palabras clave: Estela, serpiente, ofidio, cobra, Mehen, Renenutet, uróboros, renacimiento, tiempo ilimitad,
Keywords: Stela, snake, ophidium, cobra, Mehen, Renenuntet, ouroboros, rebirth, unlimited time, eternity.

El cielo se ha quedado preñado de vino, he aquí que Nut ha dado a luz a su hija la estrella de la mañana. Así que me levantaré, el tercer Compañero de Sothis de lugares limpios ${ }^{1}$.

Fintre los variados objetos que Somerset Lowry-Corry ${ }^{3}$ (1774-1841), segundo H11 Paneb preparó para su Conde de Belmore, y adquirida por el museo tumba, se encuentra una estela (fig. 1) de pie- en 1843 tras su muerte, junto a otras piezas. dra caliza que se guarda en el British Muse- La estela perteneció a Paneb ${ }^{4}$, hijo de um, EA $272^{2}$, procedente de Deir el-Medi- Nefersenut y de su esposa Iuy, un hombre que $\begin{array}{ll}\text { na. Dicha estela fue comprada por el políti- } & \text { nació hacia el año } 40 \text { del reinado de Ramsés } \\ \text { co irlandés y coleccionista de antigüedades } & \text { II y que en torno al año } 66 \text { comenzó a trabajar }\end{array}$

1 Allen 2005: 334. "The sky has become pregnant with wine, behold, Nut has given birth to her daughter the morning star. So, I will raise myself, the third (companion) of Sothis of clean places". La autora dedica estas líneas y las siguientes a Covadonga Sevilla Cueva, gran amiga y excelente profesional.

2 James 1961: fig. 4 .

3 Bierbrier 1995: 340-341. 6

4 http://www.britishmuseum.org/research/collection_online/collection_object_details.aspx?objectId=177455\&part Id=1\&searchText=PANEB\&page=1 Consultado el 10.01.2017. En los textos figura como personaje siniestro y corrupto que se vio implicado en sobornos, robos de diversos objetos y asesinatos, así como en abusos de mujeres. Sobre el

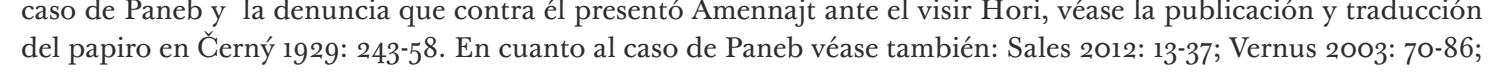
Tosi, Nicola y Bierbrier 2003: 91-98. Sobre el robo de piedra de la tumba de Sethy-Merneptah véase el papiro Salt 124 rt. 2, 5-6 referenciado en McDowell 1990: 208, 217. Desde otro punto de vista, ver el ostracon Cairo 25556, pues aquí Paneb forma parte del tribunal que juzga a hiy, pn-imn y pth-šd, en lugar de ser él el delincuente juzgado.
Traducción y descripción del texto en McDowell 1990: $25^{1-253}$.

TdE 8 (2017) - Paginas: 77 - 91 


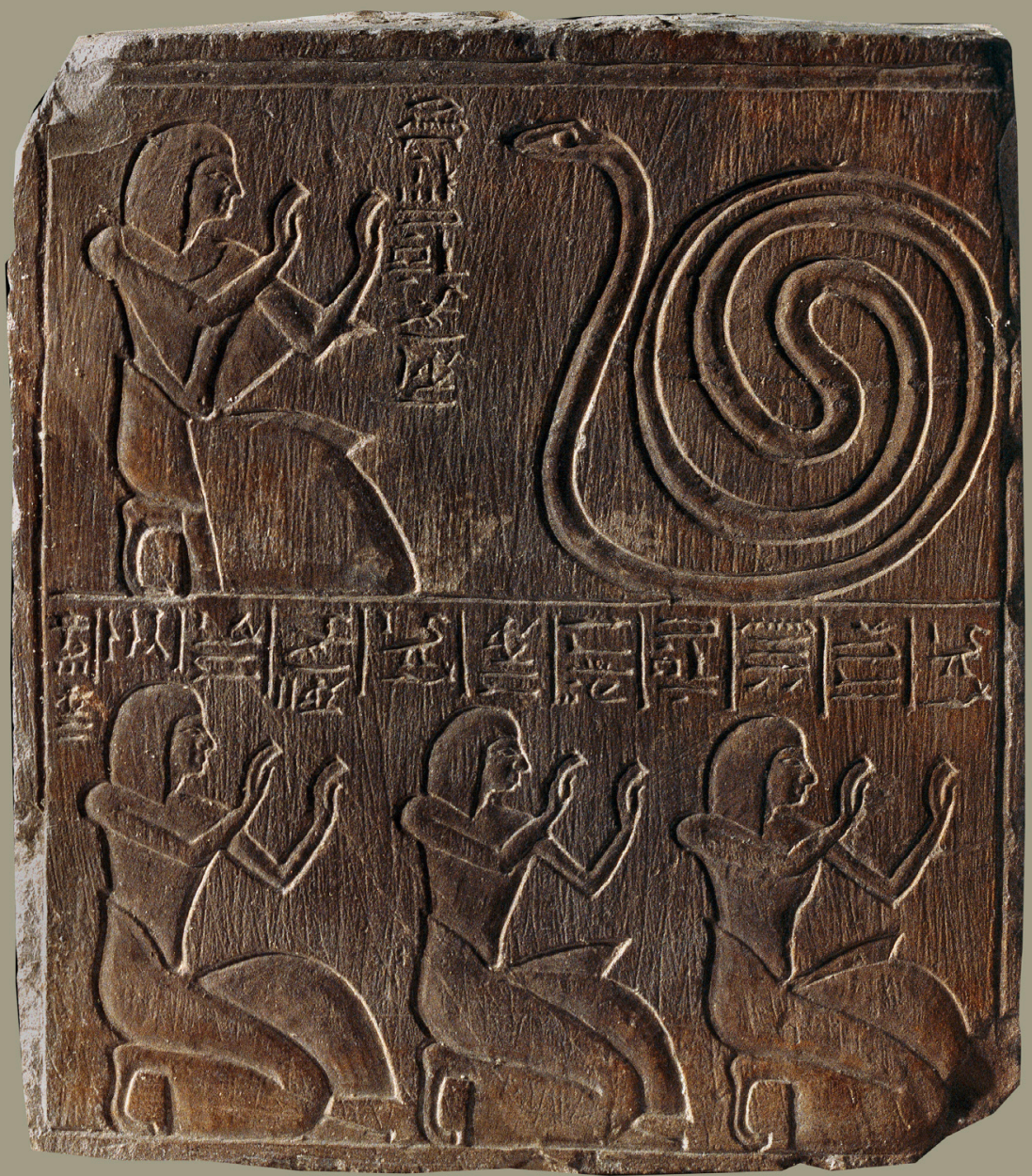

Figura 1. Estela de Paneb, Deir el-Medina. Londres, British Museum, EA 272. Con autorización del Museo.

como capataz del Lugar de la Verdad, ascendiendo bajo los reinados de Sethy II y Merenptah Siptah ${ }^{5}$. Fue el propietario de la TT 211, una de las tumbas monocromas que se

Los relieves de la estela se conservan en buen estado, sólo están ligeramente dañados los bordes y se aprecian alounas rayaduras. La pieza guarda unas proporciones armoniosas: $19,3 \mathrm{~cm}$ de alto, $17 \mathrm{~cm}$ de ancho y $6 \mathrm{~cm}$ de pro-

5 A partir del año 2 de Siptah no se conservan referencias a Paneb en Deir el-Medina; sin embargo, y debido a la poca documentación que ha llegado de este momento histórico, puede que mantuviera un cargo de categoría inferio hasta el comienzo del reinado de Ramsés III. Véase: Sales 2012: 13-37. fundidad. Está dividida en dos registros horizontales: en el superior aparece Paneb arroillado, en actitud de adoración ante una dio-

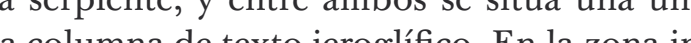
cerior de la estela se es ferior de la estela se esculpió la inagen arrote la des de sus desces en la ciudad: los sirvientes de las Dos Tierras en el Lugar de la Verdad, Aapehty, Paneb, y Nebmehyt, que se encuentran también mos-

trando su piedad religiosa hacia esta deidad ubicada en el registro superior que se presenta, como hemos indicado, en forma de ofidio. Sobre ellos hay once columnas verticales de texto en las cua co de cada uno de los mencionados personajes (fig. $)$. Las figuras y los textos, sin trazas de policromía están grabados en relieve inciso

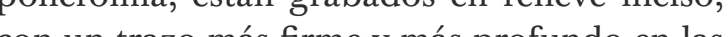
figuras que en los textos jeroglíícos.

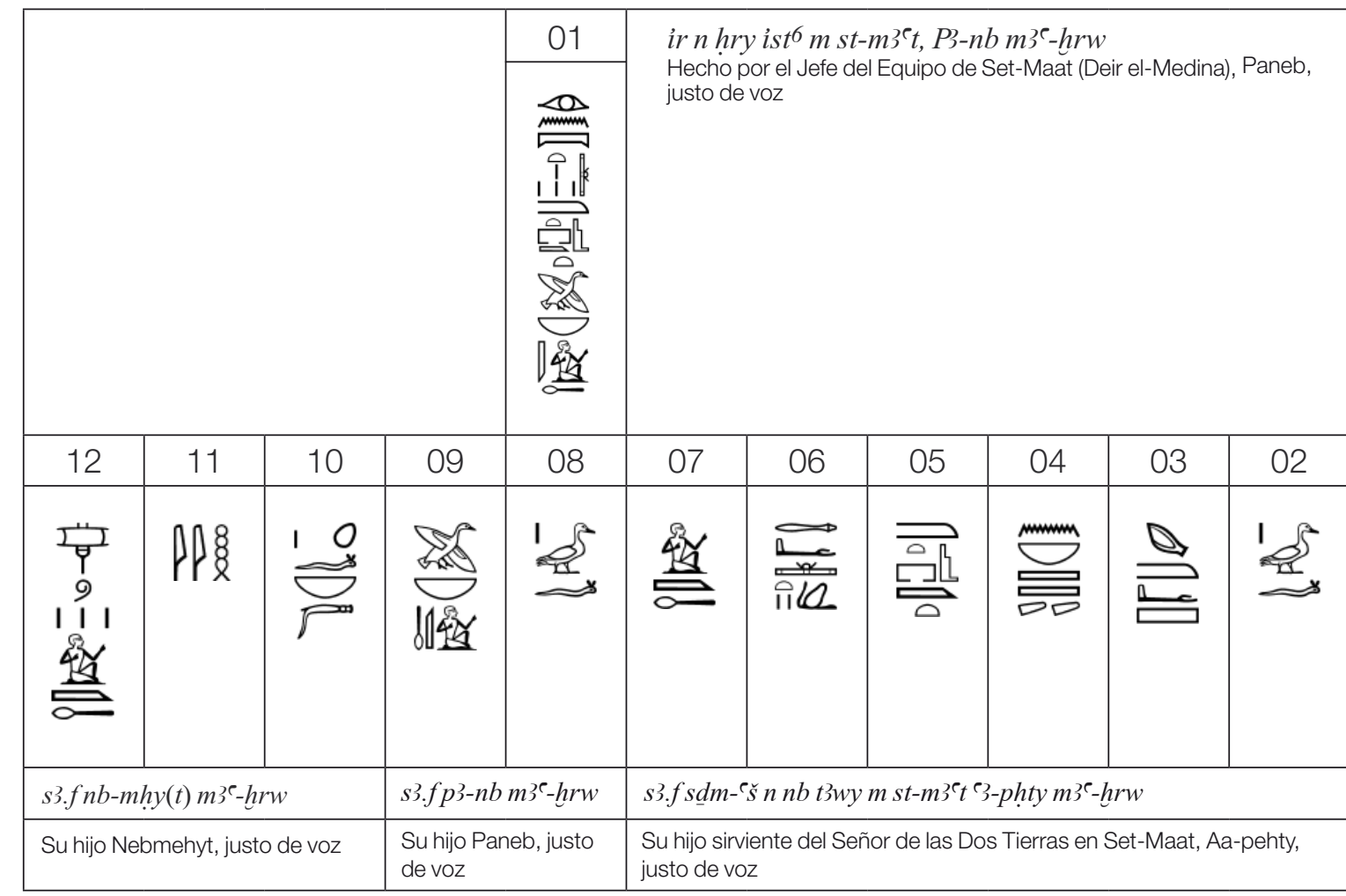

Figura 2. Disposición del texto jeroglifico, transliteración y traducción. Elisa Castel.

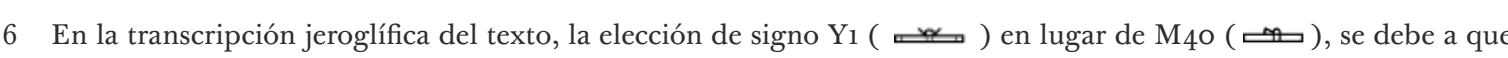
el signo en la estela se asemeja más al primero, quizá por un error del artista. Sin embargo, en la transliteración se "Jefe de los Documentos", hry mdijwt, que sería la lectura resultante si tuviéramos en cuenta $\mathrm{Y}_{1}($ ). El primer título se puede ver, por ejemplo, en la estela EA273 o en el óstracon EA 65935 del British Museum donde está escrito con el signo que corresponde. El nombre de este personaje figura en una buena cantidad de documentos, muchos de los cuales pueden explorarse en The Deir el Medina Database: http://dmd.wepwawet.nl/ (consultado 1.12.2017). 


\section{Las serpientes y la diosa}

Los motivos que tal vez llevaron a la veneración de serpientes venenosas pueden percibirse al indagar en sus rasgos naturales: por un lado, la existencia de una gran cantidad de ofidios en el Noreste de África; por otro, el hecho de que se trata de un animal que necehecho de que se trata de un animal que nece-
sita el calor del sol (al dios Ra) para activarse. sita el calor del sol (al dios Ra) para activarse. Su desarrollo y crecimiento no se interrum-
pe en el tiempo, teniendo que mudar la piel pe en el tiempo, teniendo que mudar la piel regularmente, algo que se vinculó al rejuvenecimiento, al renacimiento y, cómo no, a la renovación. Además, son reptiles capaces de captar las vibraciones y sensibles al calor que lor intenso, a veces mortal, comparable a la furia del Sol, atibuto que los llevo a penetrar en

De forma mayoritaria las serpientes, y en concreto la cobra, fueron incorporadas al panteón egipcio como entidades femeninas. Son hijas de Ra pero, a la vez, se asocian a los graneros ya que, al ser lugares donde debieron proliferar, se consideraron guardianas de los mismos.

Una de las especies de cobra lanza su veneno hacia los ojos de su ponente cuando se ve amenazada, una peculiaridad que los egipcios representaron con precisión, tanto que -a veces- se reprodujo proyectando su veneno, sustancia identifcada con los poderes dañ , susabrasa ides dios solar. La principal diferencia iconografic diferencia iconográn sa de la cobra respecto de otros ofidios consiste en que posee unas costillas cervicales que expande cuando se siente provocada, rasgo que los egipcios plasmaron claramente en varias diosas cobras, como po

ejemplo Uadyet o Meretseguer en la mayor parte de los casos en que son representadas.

Sin embargo, en la imagen que se esculpio en la esculo en la esta de estudiando, poicen en pusichón de defensa aparente, no tiene el capuchón característico que despliega, algo que sí ocurre en otras representaciones y en el texto tampoco figura su nombre.

\section{Meretseguer}

Los responsables del British Museum no plantean ninguna duda respecto a la identificación de la diosa reptil que aparece en la estela EA 272: Meretseguer, pese a que en su estela desce descabellado pensar que, al haberse creado ciala al co funcrorio, tras posilidan Amón otras posibilidades. Amón, Amenhotep I y Ahmes Nefertari, Hathor y Meretseguer, son en realidad las principales divinidades veneradas en el poblado y de todas ellas Meretseguer, por la que nos inclinamos, es la que tiene mas visos de ser la serpiente representada en la estela de Paneb.

Muchos personajes privados, especialmente en Deir el-Medina, se pusieron bajo su custodia y Paneb debió de ser uno de ellos pues, con apariencia humana o de ofidio, Meretseguer gozó de un amplio culto popur Meretsegur gozó de un anplio culto popular, como se percibe en la numerosa cantidad usión

Por otra parte, los reyes, reinas y príncipes, aunque con menos frecuencia, también Diversas publicaciones atribuyen esta serpiente a la diosa Meretseguer, entre ellas, la base de datos online del British
Museum: http://www.britishmuseum.org/research/collection_online/collection_object_details.aspx?objectId=177 455\&partId=1\&searchText=PANEB\&page=1; véase también: Shaw y Nicholson 1995: 263 o Bierbrier 1982: 30 y pl. 75.

la incluyeron en sus tumbas ${ }^{8}$, por ser una divinidad funeraria protectora fuertemente implantada en la orilla occidental de Tebas, gozando también del reconocimiento de la élite cortesana.

Aceptando esta identificación, lo excepcional de la pieza considerada es que, hasta el momento, desconocemos la existencia de ningún otro relieve, estatua o pintura donde se muestre a Meretseguer enrollada en tres vueltas sobre sí misma, formando círculos concéntricos, pues lo habitual es encontrarla representada exhibiendo dos o tres ondulaciones en su cuerpo (fig. 3). También se reprodujo erguida, claramente como una cobra en actitud de defensa y con el cuerpo recogido bajo ella sobre la superficie de la tierra (fig. 4)

Meretseguer es una diosa solar tebana, hija de Ra, que se manifiesta bajo el aspecto de serpiente, de mujer con cuerpo -o no- de ofidio, incluso en forma de esfinge ${ }^{9}$ y que suele coronarse con un modio y dos altas plumas o con disco solar y cuernos de vaca, emblema este último de la fertilidad y la complementariedad.

La divinidad, documentada desde el reinado de Senusert III ${ }^{10}$, parece ser una forma local de Hathor ${ }^{11}$ que incrementó su culto durante el período ramésida, época en la que se

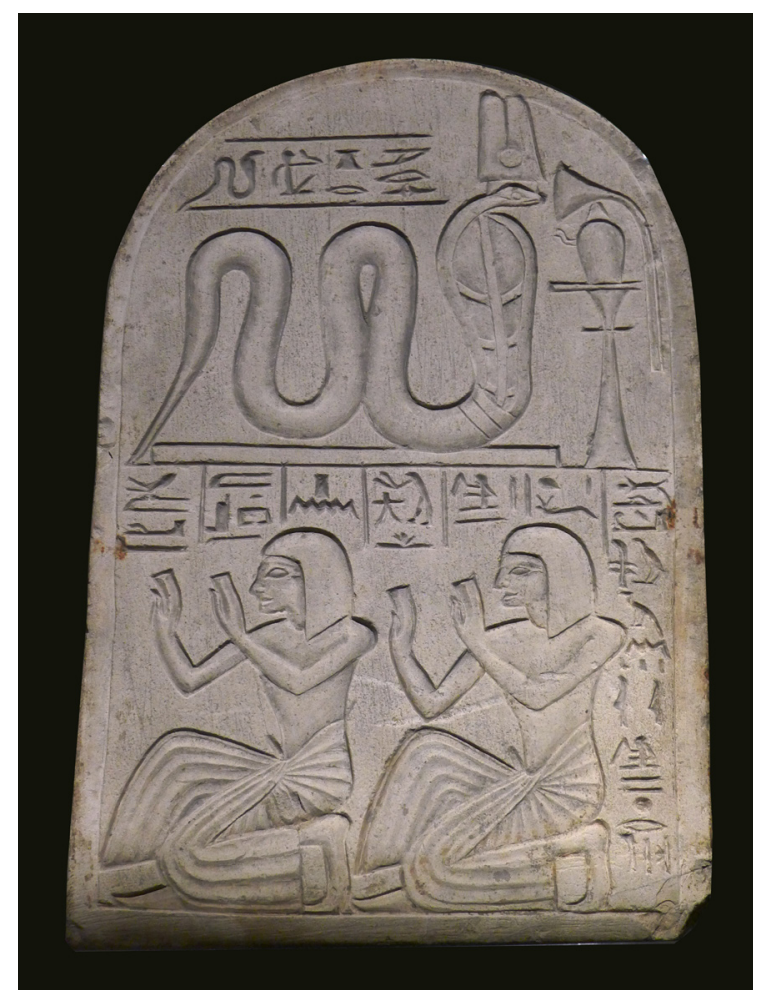
Figura 3. Estela de Pendua, Deir el-Medina. Turin, Museo Egizio, N.50061. Meretseguer con el cuerpo
tres ondulaciones. Fotografía de Elisa Castel.

esculpió la estela ${ }^{12}$. Habitaba en la cúspide de la montaña tebana y tenía un santuario sem

Respecto a las tumbas del Valle de los Reyes donde se encuentra: Porter y Moss 1973: 501, primer corredor de la tumba de Ramsés XI (KV 4 ); Porter y Moss 1973: 514, corredor F de la tumba de Ramsés VI (KV9); Porter y Moss 1973: 502 corredor A de la tumba de Ramsés IX (KV6); Porter y Moss 1973: 514-517 vestíbulo E y en el corredor descendente F y en los pilares de la cámara del sarcófago de la tumba de Ramsés VI (KV9); Porter y Moss 1973: 529, corredor C de la tumba de Tausert (KV14); Portery Moss 1973: 546, corredor del enterramiento del príncipe Montuherjopeshef ( $\mathrm{KV}_{19}$ ). En el Valle de las Reinas: Porter y Moss 1973.753, pilar A del vestibulo de Parahirunemef ( $(\mathrm{V}$ 42); Porter y Moss 1973:754, vestíbulo de la tumba de Sethirjopeshef ( $\left({ }^{4} 43\right)$; Porter y Moss 1973: 767 vestíbulo de Henutmira, etc.

9 Así se muestra en una estela guardada en la colección egipcia de los Musei Vaticani ( $\mathrm{n}^{\circ}$ 170). Véase en: Bruyère 1930: 115 .

10 Bruyère 1930: 245

11 Hathor se relaciona con Meretseguer en una estela del Egyptian Museum de El Cairo (JE 72018) en la que se encuentran las dos diosas, una con cabeza de cobra y la otra con apariencia humana, dando de mamar a un niño. Junto a la segunda aparece el nombre de Hathor y figura con "su bello nombre de Meretseguer"

12 Jauhiainen 2009: 159-160. La importancia del culto a Meretseguer en la aldea de Deir el-Medina se manifiesta no sólo en estelas y mesas de ofrendas, sino también en las relaciones de grano que le entregaban a modo de ofrenda: 


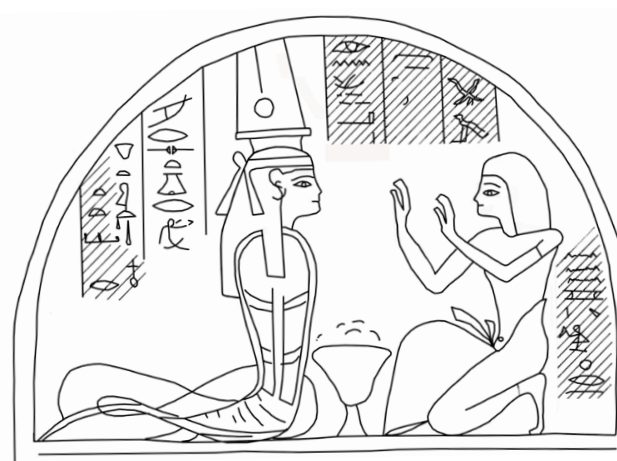
Figura 4. Registro superior de la estela ramésida de
Penpahapi, Deir el-Medina. Londres, British Museum, EA sos oratorios; no en balde su nombre significaba "Aquella que ama el silencio". Era, en fin, ba "Aque la protectora de los enterramientos del Oeste
de Tebas. do ramésida, fue también una deidad ligada a rupestre en sus proximidades, así como diver-

Asociada a la necrópolis durante el perío-

nociones de justicia y de medicina ${ }^{13}$ pues se interpretó que era protectora del bien y por tanto atacaba a los que cometían faltas, pudiendo causarles la ceguera o la muerte. Y como discausarles la ceguera o la nuerte. Y como dis-

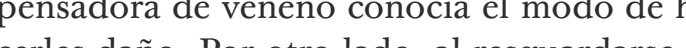
cerles daño. Por ot la tierra se pensó que cimientos ocultos

Meretseguer se representa habitualmente de forma muy realista con aspecto de $\operatorname{cobra}^{14}$ del gé nero Naja, un elápido que alcanza una longitud de poco más de un metro pero que, en casos excepcionales, puede llegar a los 3 metros $^{15}$. En e arte egipcio suele aparecer en posición erguida y mostrando su característico capuchón desplegado en actitud de defensa. Es cierto que en alounos casos la encontramos representada en reposo, sin que podamos saber el motivo por el que los mo plasmación gráfica de la diosa. Por tanto, observan-

Texts listing grain rations to various deities of Deir el Medina indicate that the cults of Meretseger and Hathor received the most governmental support. However, the references to the divine offerings delivered for the cult of

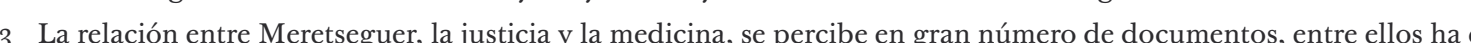
destacarse la estela del Servidor del Lugar de la Verdad, Neferabu que se conserva en el Museo Esizio de Turín que lleva el $n^{\circ} 5005$. Véase en: Tosi 1972: 286. La pieza procede Deir el-Medina y en ella se agradece a la diosa su intervención para la cura de un mal -atribuido a un castigo divino- y se advierte del peligro que supone cometer faltas. El texto jeroglííco se distribuye en 17 registros verticales largos y 3 más cortos y en él puede leerse:

Recitare un inno alla Cima d'Occidente. adorare il suo Ka. Recito un inno, ascolta il mio appello, perché <feci> la giustizia in terra. Dedicato dal servidore nella Sede della Verità Neferabu giustificato. Ero stato uomo ignoran senza senno, che non distingueva bene da male. Commisi il peccato di disobbedienza contro la Cima ed essa n inflisse un castigo. Ero nella sua mano notte e giorno. Stavo seduto sul mattone come la partoriente; supplica il soffio e non venne da me. Mi umiliai (?) alla Cima d'Occidente, grande di potenzza, e ad ogni dio ed ogni dea. La Cima batte con il colpo di un leone feroce. Essa perseguita chi le disubbidisce. Supplicai la mis Signora e h trovai che venne da me quale dolce vento. Fu indulgente verso di me dopo avermi mostrato la sua mano. Ritorno da me propizia. Essa mi fece dimenticare il male, che era nel mio cuore. Ora, la Cima d'Occidente è propizia se la si supplica. Disse Neferabu giustificato, dicendo: ecco, odano le orecchie tutte (dei?) viventi in terra: guardater dalla Cima d' Occidente. Traducción tomada de: Tosi 1972: 95

14 Las cobras, no así otros ofidios, sirvieron como manifestaciones de entidades divinas femeninas. Véase: Bruyère 1930: 205-108.

15 Sobre las cobras véase: Castel 2009: 133-135; Houlihan 1996: 168-185; relacionada con Meretseguer en: Castel 20o1 en cobra posteriormente.

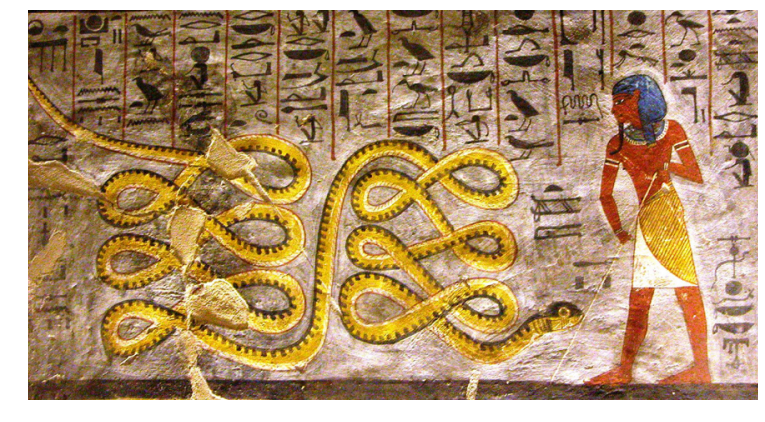

Figura 5. Serpiente Apofis
Fotografia de Elisa Castel.

apariencia pacífica. Por lo demás, bajo su imagen ofidiomorfa aparece como un reptil muy largo,

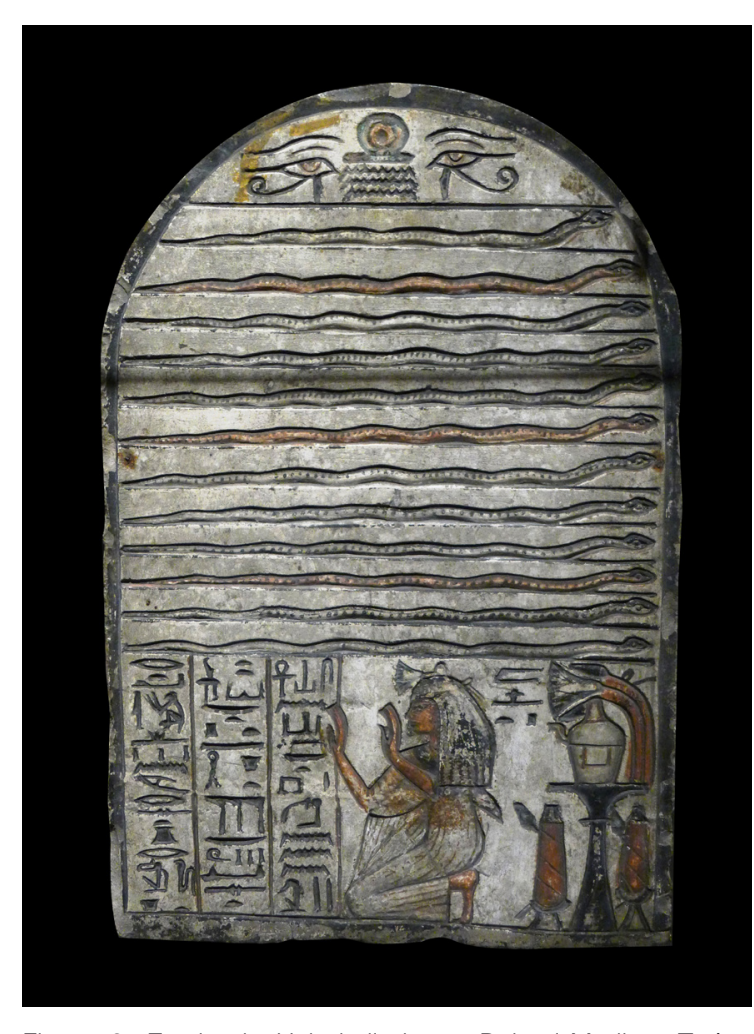

Figura 6. Estela de Uab hallada en Deir el-Med
Museo Egizio, N.50060. Fotografía de Elisa Castel. a veces sin el capuchón desplegado, aunque sí se muestre con la cabeza ligeramente más grande. Sin embargo, es así la cabeza de Apofis, un ofidio que se ha identificado habi-s . As con un cuerpo mucho más largo.

Asimismo, también hallamos a Meretseguer en actitud de reposo. Como ejemplo podemo recordar una de las estelas donde encontramo un número variable de serpientes ondulantes (fig. 6) sobre la línea de tierra, dispuestas en registros horizontales. La imagen difiere sustancialmente de aquellas en las que tiene un aspecto mucho más agresivo.

\section{Ofidios enroscados sobre sí mismos}

Si observamos con detalle cierta iconografía egipcia quizá podamos desvelar algunas cuestiones relativas al significado de la imagen que estamos analizando. Los ofidios enroscados sobre sí mismos proporcionan un espacio protector y a la vez un circuito mítico de renacimiento. Así lo apreciamos en ciertas paletas de esquisto ya desde el período Predinástico (fig. 7) y en los amuletos y tableros de juego mehen que encontramos desde el periodo Predinástico hasta el siglo V a.C. (fig 8). Se observa también que es un ofdio (ing. 8).

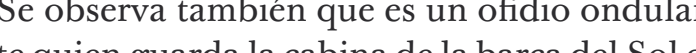
te quienguarda la cabina dela bar as tumbas tebanas del Reino Nuevo (fig. 9) o una cobra que rodea el disco solar (fig. 10) describiendo un circlo que no tiene fin. Co simbolismo semejante hallamos ofidios protegiendo la cama funeraria de Sennedyem ${ }^{16}$ (fig. 11), aunque en este caso, en realidad, son dos serpientes, una ofidiocéfala y otra con cabeza de chacal, guardando el cuerpo del difunto situadas a ambos lados de la cama y con las

16 Quiero agradecer a Noor Hassan, Marta Saura y Jaume Vivó el haberme proporcionado fotografías de esta pieza que actualmente ya no está expuesta en el Museo Egipcio de El Cairo. 


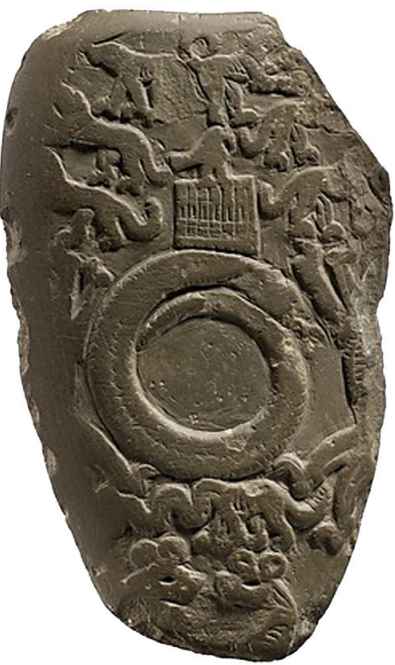

Figura 7. Paleta Predinástica ceremonial. Finales de Nagada III. Nueva York, Metropolitan Museum, MM 28.09.8. Tomado de
http://www.metmuseum. org/art/collection/search/547390.

colas y las cabezas enfrentadas ${ }^{17}$. El nombre de estas serpientes es, en este caso, irrelevante porque lo que aquí nos incumbe es la herramienta utilizada: dos serpientes ondulantes formando un recinto protector ${ }^{18}$

Los ejemplos donde el ofidio actúa formando un escudo circular que protege y favorece

se repiten en la iconografía egipcia con una frecuencia significativa pero, de forma creciente lo hallamos en la decoración pariental de las tumbas del Valle de los Reyes ${ }^{19}$ Otro emblema digno de tenerse en cuenta se halla en los chrculos que marcan los nueve caminos concéntricos de fuego y tierra de la serpiente Mehen ${ }^{20}$ en el ataúd de Sepi ${ }^{21}$, de la dinastía XII, que se guarda en el Egyptian Museum de El Cairo, (fig. 12), y en el uróboros $(s d m r 3)$, cuya imagen fue empleada por primera vez en la decoración del panel exterior

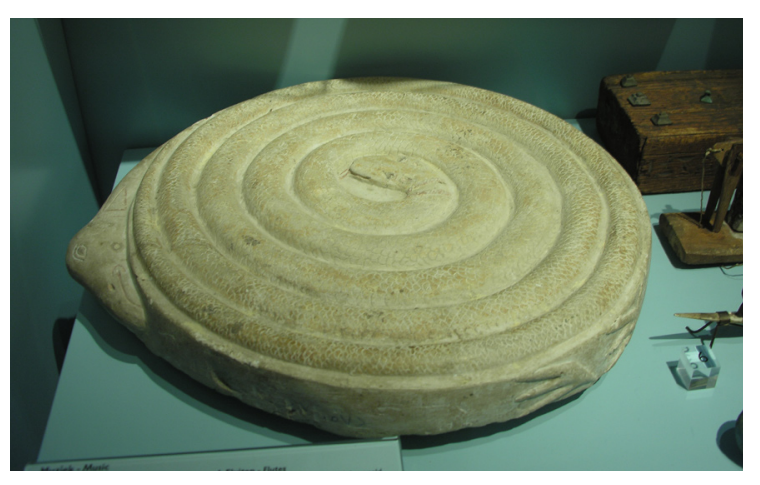

Figura 8. Juego-mehen. Dinastías III-VI. Leiden, Rijksmuse
van Oudheden, F 1968/3.1. Fotografia de Elisa Castel.

17 En la cama la serpiente puede haberse asociado a Qebehut sin que afecte a nuestra hipótesis, según se colige de ciertas formulas de ascensión de los Textos de las pirámides de Pepy I y Merenra (PT 473 y PT 619). Por ejemplo, el muro oeste del vestibulo de la piramide de Pepy I dice: "His face is that of a jackal, his middle is that of Qebehu" y en la pared norte de la pirámide de Merenra se indica: "Your face is that of a jackal, your middle is that of Qebehut, your rear is a broadhall". Véanse las formulas citadas en: Allen 2005: 186, 235

18 Las dos líneas de texto que hay en el lecho no recogen el nombre de estas dos serpientes, sólo indican: 1. "El Osiris, el sirviente del Señor de las Dos Tierras, Sennedyem". 2 "El venerado, Osiris Sennedyem, justificado". Véase Mahmoud Abd el-Qader, 2011: 186. Véase también en: Saura i Sanjaume 2006: 411, 525.

9 En las tumbas del Valle de los Reyes este simbolismo es habitual. Lo encontramos, por ejemplo, en las horas sexta, séptima y octava de la Amduat de las tumbas $\mathrm{KV}_{34}$ y KV 35 , pertenecientes a Thutmés III y de Amenhotep II, y posteriormente, en las ramésidas. Vease en el hipogeo de Ramsés VI, Piankoff 1954: 274, fig. 79, donde en la rampa can elo cor Tis is the body of

y of Khepri in his own flesh. Many Faces guards him. He is like this, his tail is in his mouth. This . r place in the Netherworld.

Tambien son reseñables las escenas recogidas en Piankoff 1954: figs. 80, 127, 131, 133, entre otras. En todas ellas el ofidio rodea y protege creando un espacio para la divinidad.

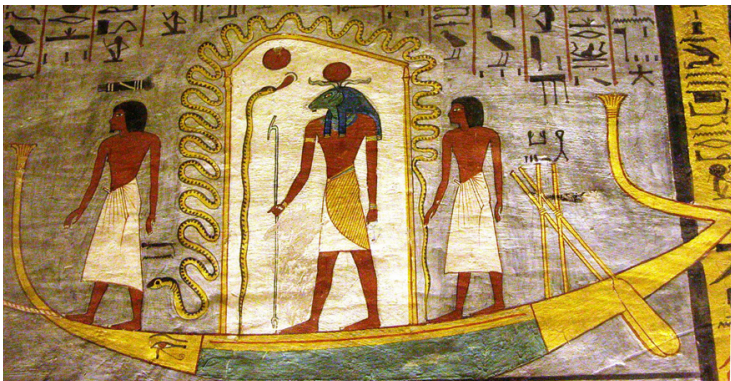

Figura 9. Serpiente protegiendo la cabina del Sol. Tumba d

izquierdo de la segunda capilla de Tut-anjAmón (fig. 13) o en el papiro de la dama Herub $^{22}$ (fig. 14). Uróboros significa "serpiente con la cola en la boca" o "fuera de la oscuridad", refiriéndose en este caso a la salida de la ial, ligado a concep de modo que as se converta ne la epifanía de volver a comenzar y de renaciniento en eterna repetición ${ }^{23}$

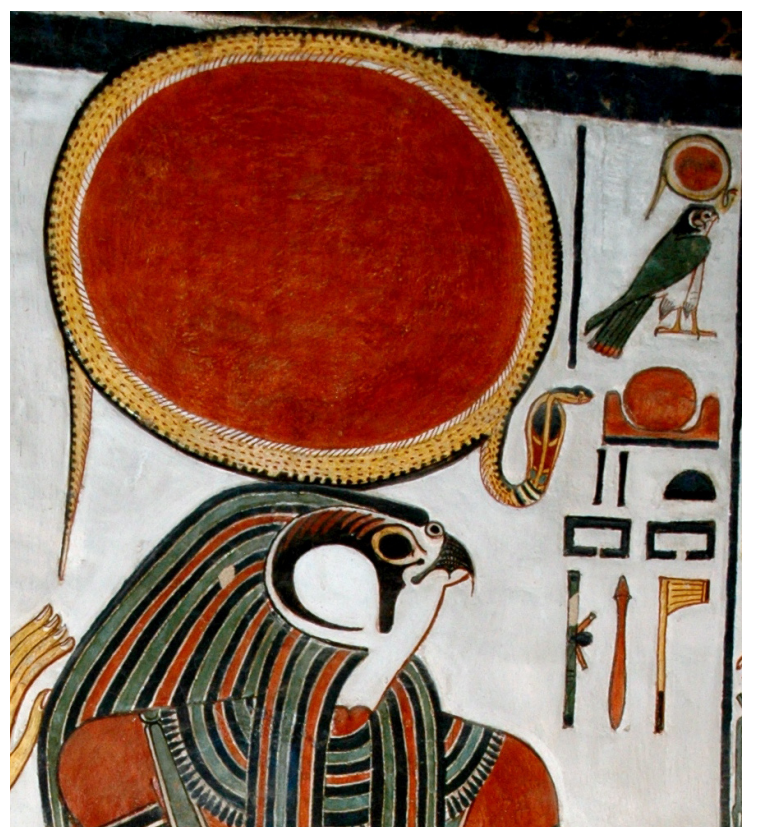

Figura 10. Cobra protegiendo al disco solar. Tumba de
Nefertari, QV66. Reino Nuevo. Imagen parcial tomada de: Nefertari, QV66. Rein N
McDonald 1996:67.

20 Cuatro son caminos rojos de fuego y cinco son negros, quizá de tierra, separados por líneas blancas, en cuyo centro se encuentra una figura frontal de Ra-Osiris con corona atef, complementada por debajo de los

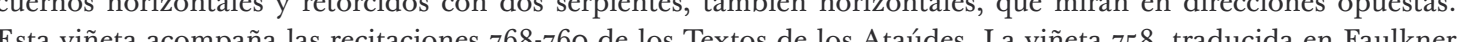
1977: 290 y recogida en el ataúd dice lo siguiente: On the throne of the god: Myriads of years. On the right edge of the ovals: The paths of fire. These paths guard the larboard side of the bank of the Coiled One, who makes a circle in a myriad after a myriad (of years). Sobre este particular véase: Piccione 1990: 44:

These spells depict a realm of the afterlife in which the bark of Mehen encircles nine concentric roads, four of which are specifically roads of fire, which it circumnavigates for millions of years. In the vignette of the spell, the four roads of fire are depicted in red paint, and they alternate with five black roads (fig. I). According to the texts, upon these roads of Mehen are "gates that turn away" (sb3w stnmw).

En relacion con este relación con el viaje y resuracto muñecas rusas, revelan los mismos círculos receneradores al ser encajados unos en otros. V'́ase: Bettum 2017: 76, 81.

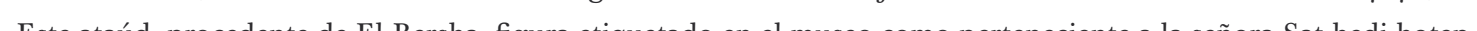
Pirelli 2000: 126-127, donde se atribuye al general Sepi III, al haberse encontrado en el interior de su tumba.

22 La presencia del uróboros, entendido como espacio sagrado y protector, permanece en la imaginería egipcia a lo largo de toda su Historia. Es frecuente encontrarlo en los hipogeos del Valle de los Reyes a sobre la supieficie de capillas, Un estudio completo de este motivo iconográfico puede consultarse en Reemes 2015: 2-4, fig - 1-4 En las ilustraciones se encuentran numerosos ejemplos de la iconografía egipcia antigua y algunos de los que se recogen, posteriormente, fuera del territorio egipcio. 


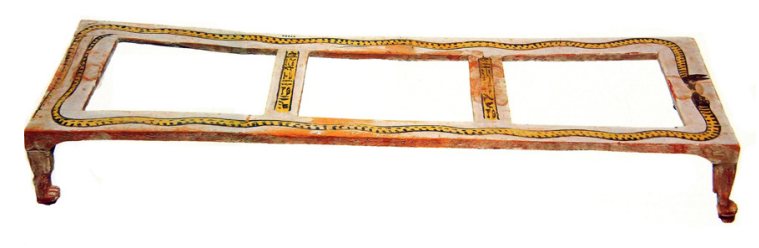

Figura 11. Cama de Sennedyem. Dinastía XIX. El Cairo, Museo
Egipcio, JE 27254. Adaptada de Hornung 2002: 148-149.

Similar expresión se encuentra en el templo de la diosa Isis en Filé, donde la serpiente protege la caverna de la que emana el agua del Nilo, describiendo con su cuerpo también un círculo defensivo (fig. 15)

Teniendo en cuenta que las serpientes sirvieron para expresar el renacimiento y el rejuvenecimiento, y que los círculos constituyen un poderoso espacio sagrado-protector y de incubación, quizá podamos empezar a considerar esta imagen de Meretseguer, anormalmente larga y con su cuerpo formando vueltas sobre sí mismo,

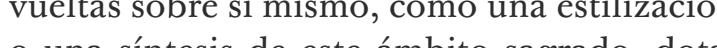
da de poder regentador $y$ puesta en conexión con la infinta duracion del tiempo, como los otos me Ras anterís. Es la hija de Ra, es además una parte del propio dios y su conocimiento de lo ctónico aporta un mayor sentido a la hipótesis que aquí presentamos.

A tal propósito, podemos aludir a otras figuras: el tablero de juego mehen que vimo antes, un óstracon procedente del Valle de los Reyes que se conserva en el Egyptian Museum de El Cairo ${ }^{24}$, en el techo del corredor $\mathrm{C}$ de la tumba de Ramsés VI (fig. 16) o en la cámara del sarcófago de Ramsés IX (KV6). En

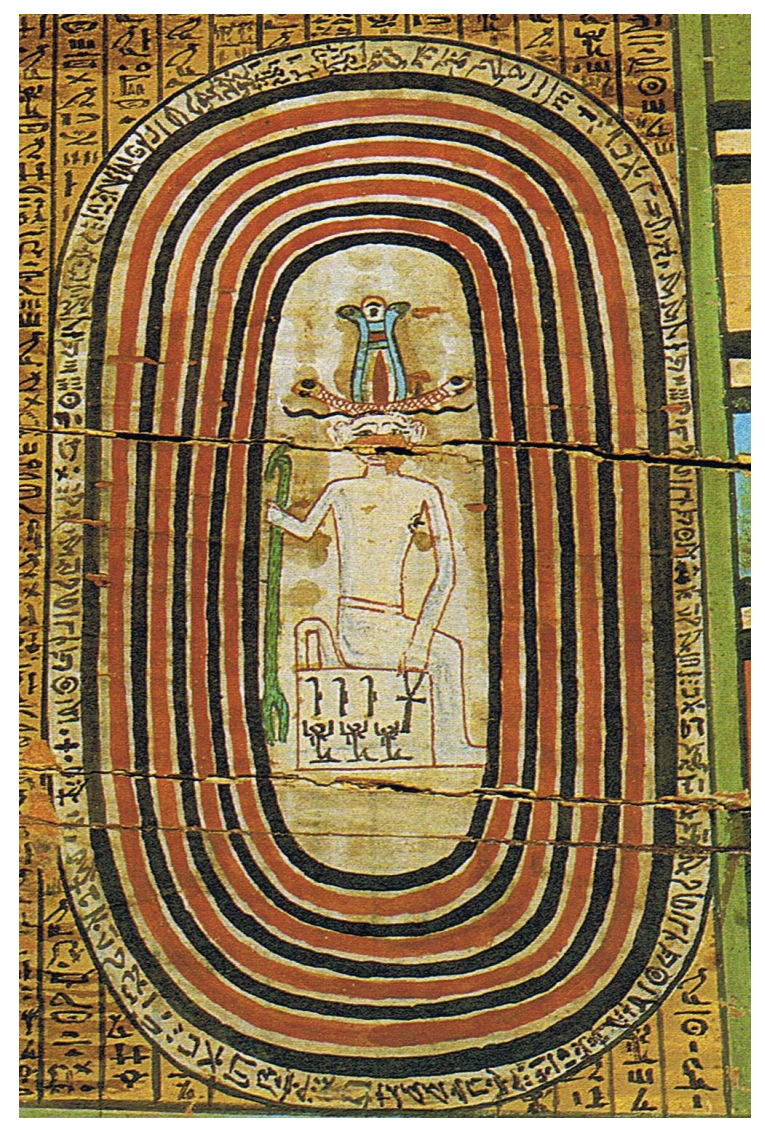

Figura 12. Viñeta del Libro de los Dos Caminos del ataúd de Sepi. Dinastia XIII EI Cairo, Museo Egipcio, JE. 32868. Imagen

los tres últimos se muestra a una mujer de frente cuyo vientre, en forma de círculo, guarda al bebé solar.

Y si entendemos a Meretseguer como una forma de Hathor podíamos asociar el concepto con la gruta que se abre en el Valle de las Reinas, creando una doble herramienta de

23 Quirke 2003: 158:

Al ser un habitante de la tierra, la serpiente podria representar también a la divinidad primordial como serpiente pinigenia, en imágenes como el uroboros, o serpiente que se traga su propia cola, símbolo de eternidad que aparecía cerca del dios sol recién nacido.

24 El Cairo, Museo Egipcio, CGC 25074

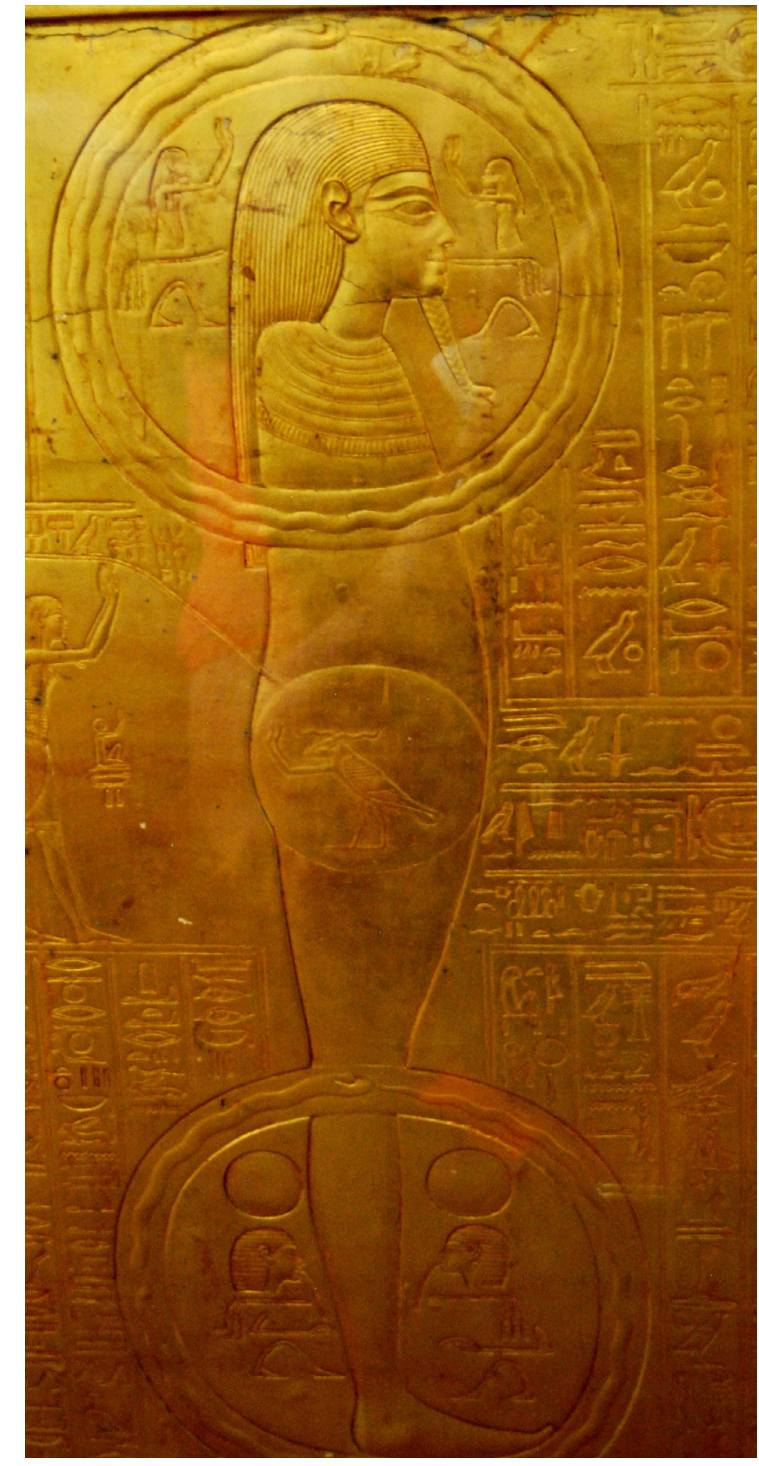

Figura 13. Dos uróboros en la segunda capilla de Tutanjamón.
Dinastía XVIII. El Cairo, Museo Egipcio, JE. 60660. Fotografía Dinastia Xini. É Cairo, Museo
de Francisco Pérez Vázquez.

círculo protector, por otro lado, semejante a la simbología abstracta que Paneb quiso imprimir en las mir en las vueltas concé
piente. Según Bruyère:

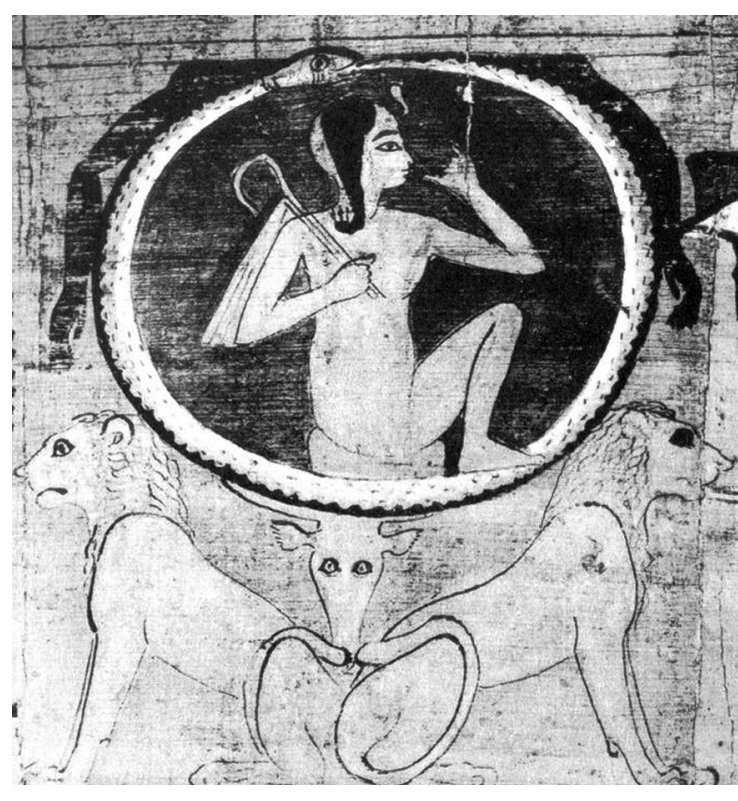

Figura 14. Figura 14.- Uróboros en el papiro de la dama Herub.

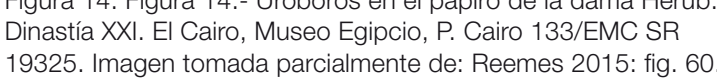

Ainsi pourrait-on interpréter l'épithète "maîtresse des generations et des manifestations sans nom-

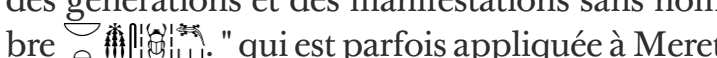
seger,

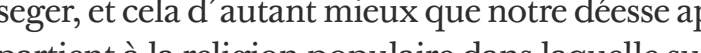
dans laquelle su tout la multiplicité des épiphanies divines est un fait constant chez tous les peuples ${ }^{25}$.

Partiendo de la base de que los antiguos egipcios emplearon distintas formas y expresiones para llegar a un concepto determin do atendiendo a la pluralidad de significados, la cobra habría servido como emblema de pensamiento religioso egipcio para expresa similares mensajes transcendentes, independientemente del nombre que llevara ${ }^{26}$. Por otro lado, su frecuente identificación con Renenutet, a modo de forma combinada y por tanto su relación con el cuidado del niño yel dif to renacido, está docula 


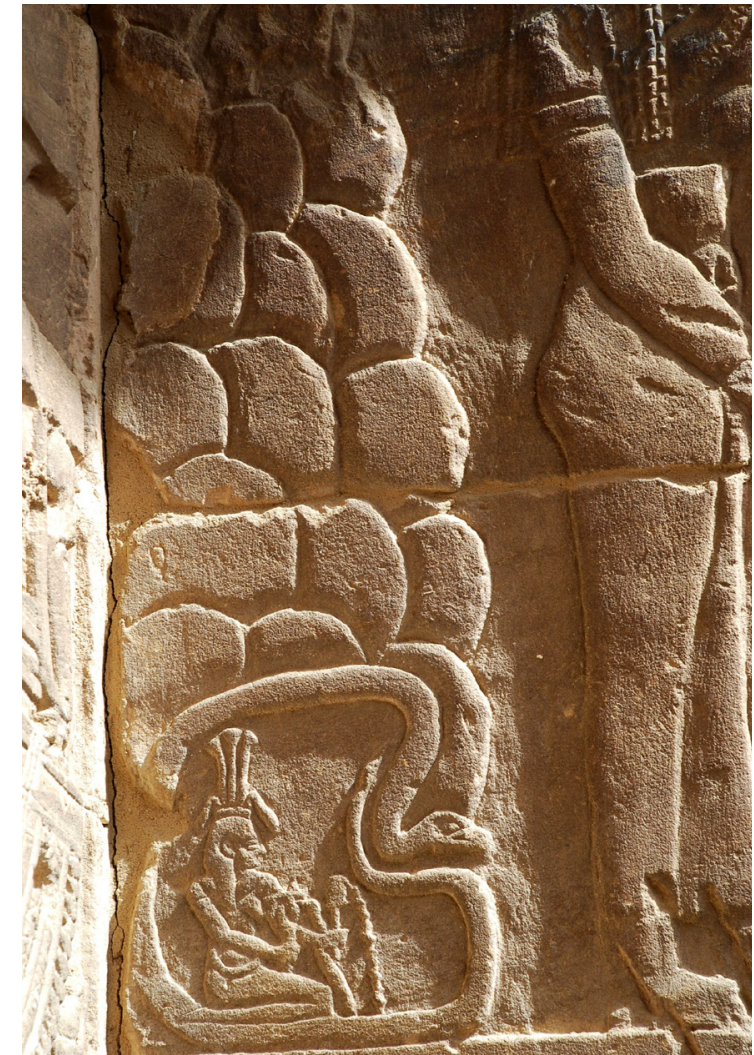

Figura 15. Dios Hapy en su caverna, protegido por el ofidio.

en la estela de Ken (fig. 17), conservada en Burdeos, donde Renenutet/Meretseguer recibe el epíteto de $H t p y^{28}$, afianza la idea de que los diferentes nombres y epítetos que re-

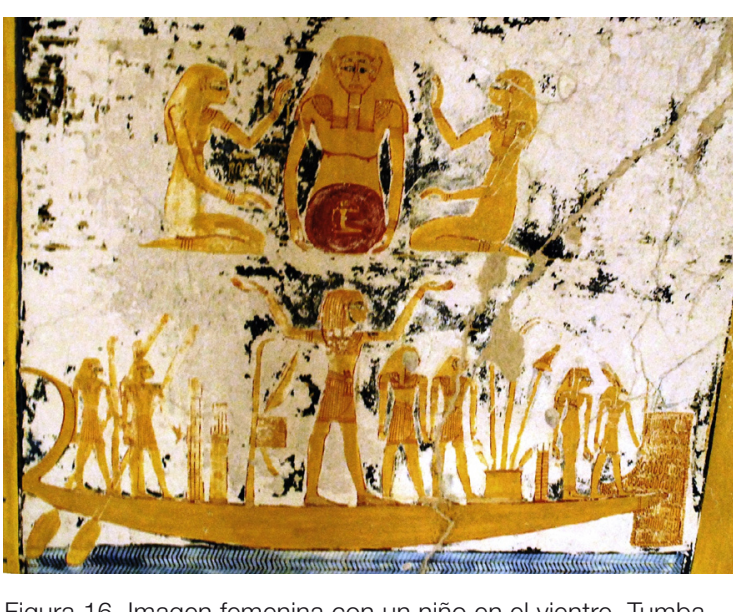

Figura 16. Imagen femenina con un niño en el vientre. Tumba
de Ramsés VI, KV9. Reino Nuevo. Fotografía de Antonio Lobo.

que Meretseguer tiene como uno de sus títulos numerosos nacimientos (ran setido esperado por el difunto, los anhelos de éste relativos al Más Allá: tanto el renacimiento continuo como fosis que precisa para afrontar las dificultades que tendrá que atravesar en su Viaje Ultratumba.

\section{Conclusiones}

Pese a que los egipcios fueron unos magníficos observadores de la naturaleza, el universo cibe la divinidad considerada (recordemos

26 Johnson 1990: 4, 11. En relación a la cobra como ureus: esta autora menciona:

In the author's opinion, the evidence confirms that no matter what the uraeus is called, or where it appears, all represent
goddess.

Este concepto puede extenderse a las cobras en general. Vernus y Yoyotte 2005: 322, 331-332:

Les dieux ophidiens de sexe masculin, serpents ordinaires, et les déesses incarnées dans le prestigieux élapidé possèdent les mêmes athibuts en remplissent les memes fonctions: tous et toutes sont pareillement redoutables,

27 Sadek 1987: 118-125. Picci 2006: 190.

28 Hannig 1997: 569: Der Gnädige, epíteto de la diosa Úreo.

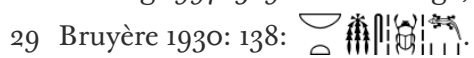

distorsionado. Se plantea la duda de si en ciertos casos, como es el de la imagen de Meretseguer que figura en esta estela, todas las ser-

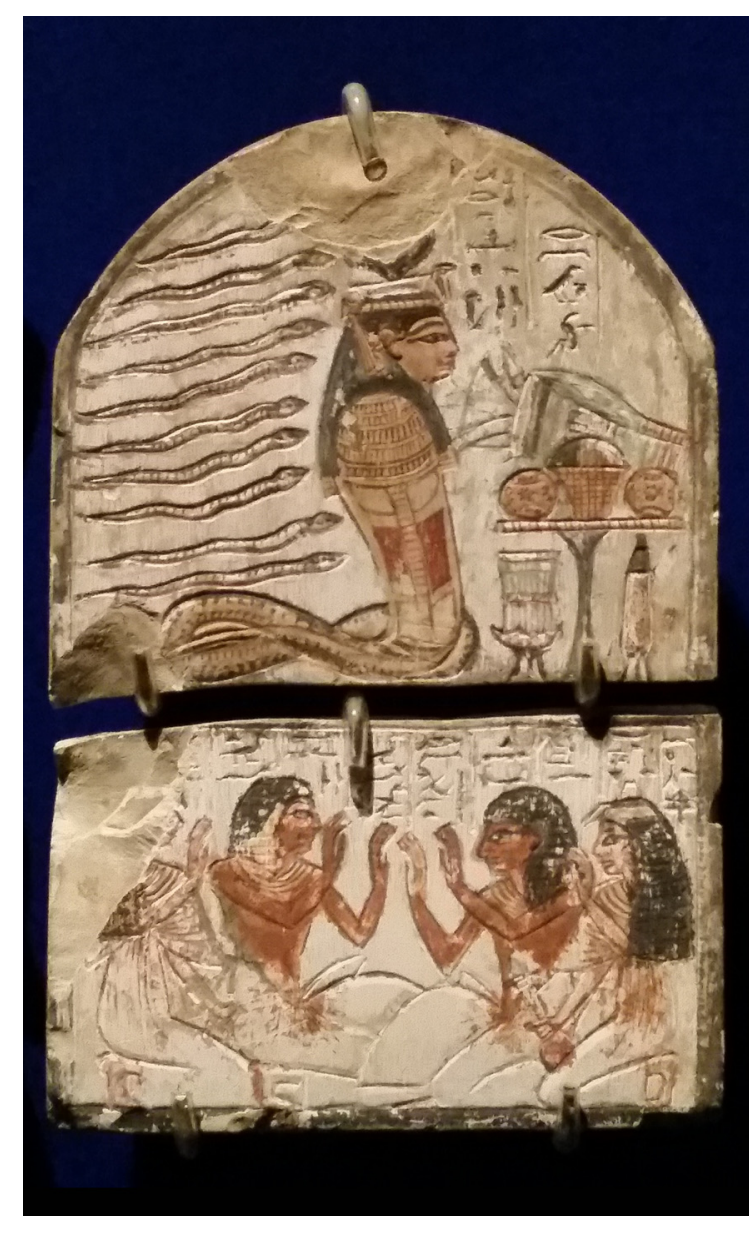

Figura 17. Estela de Ken, Deir el-Medina. Dinastías XVIII/XIX Burdeos
Castel.

pientes en las que se manifiesta la diosa fueron cobras y que su representación iconográfica no se debió a un error del artista. ¿ Sería su intención mostrar a otro ofidio sin que el discurso plástico perdiera sentido? Pero si entendemos

30 Desroches-Noblecourt 1990 que realmente es una serpiente del género $\mathrm{Na}$ ja, podemos conjeturar que existió una clara intención simbólica para mostrarla de un modo u otro.

Los giros que describe su cuerpo en la estela de Paneb pueden encontrarse en otros paralelos en los que claramente simbolizan concepciones de protección, renacimiento y tiempo ilimitado, tal y como ocurre con el uróboros, los tableros-mehen o en el ataúd de Sepi. Si aceptamos que estos últimos servían como rito de paso al Más Allá y que su configuración se asemeja al cuerpo de Meretseguer que aquí se estudia, si entendemos que la diosa a veces se equiparó a Renenutet, que la diosa combinada Renenutet/Meretseguer también estuvo unida a ideas de renacimiento y que, a su ve unica a ideas de re form el oeste de Tebas, podríamos dar un paso és

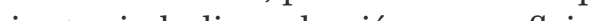
reste sinbolisno lo vicranos reflejado en la gruta que encabeza la necropolis del Valle de las Reinas, tal y como argumenta Desroches Noblecourt $^{30}$

Si la serpiente que eligió Paneb para grabar en su estela ha de identificarse o no con una cobra, es algo que excede de este trabajo. Lo que sí pretendemos proponer es que las vueltas de su cuerpo van más allá de una mera licencia artística, ofreciendo al fallecido el poder de las serpientes, a la vez que la protección de la deidad y el proceso que conducía a la eternidad que todo egipcio esperaba conseguir in segur, independ tio recibie cominado por elsmolo de lo envolvente que en sí mismo ofrece un espacio mágico y energético de gran potencia, tal y como se percibe en el óstracon de El Cairo, en la barca de Ra, en el disco solar sobre su cabeza del sol, en la cama de Sennedyem o en la protección ejercida sobre la caverna de Hapy. 


\section{Bibliografía}

AlLen, J.

005 The Ancient Egyptian Pyramid Texts (Writings from the Ancient World 23). Atlanta.

Assman, J.

1995 Egyptian Solar Religion in the Nere Kingdom (Studies in Eoyptology Series). London, New York.

Bettum, A.

2017 "Nesting: the development and significance of the yellow-type coffin en (eds.): Proceedings of the First Vaticun Coffn (enference 19-22 June 2013, Cittì del VatiConference.19.22
cano: $71-82$.

BIERBRIER, M.L.

1982 Hieroglyphic Texts from Egyptian Stelae, etc., Part 10. London

1995 Who Was Who in Egyptology. London.

BRUYÈrE, B.

1930 Mert Seger à Deir el Médineh. Le Caire.

\section{Castel, E.}

2001 Gran Diccionario de Mitología Egipcia Madrid.

2009 Diccionario de signos y símbolos del Antiguo Egipto. Cuenca.

ČERNÝ, J.

1929 "Papyrus Salt 124 (Brit. Mus. 10055)", fEA 15: $243^{-2} 258$ y pl. XLII-XLVI.

Desroches-Noblecourt, Ch.

1990 "Le message de la Grotte Sacrée", Dossier d'Archéologie 149-150: 4-21.

FAULKNER, R.O.

1977 The Ancient Egyptian Coffin Texts. Vol II. Spells $355-787$. Oxford.
HANNig, R.

1997 Grosses Handwörterbuch Ägyptisch-Deutsch (2800-950 v.Chr.) (Hannig-Lexica 3). Mainz, $2^{\mathrm{a}}$ ed.

HORNUNG, E.

2002 The Quest for Immortality. Treasures of Ancient Egypt. New York.

Houlinan, P.F.

996 The Animal World of the Pharaohs. London.

James, T.G.H

Hieroglyphic Texts from Egyptian Stelae, etc. Part I. London, 2nd edition.

JAUHiAINEN, $\mathrm{H}$.

2009 "Religious Buildings at Deir el-Medina", en: R. von Preys (ed.): Ägyptologische Tempeltagung. Structuring Religion (Konigtum,

2). Wiesbaden:

HNSON, S.

1990 The Cobra Goddess of Ancient Egypt. Predynastic, Early Dynastic and Old Kingdom Periods. London.

MCDonaLd, J.K

1996 House of Eternity. The Tomb of Nefertari. Los House of Elen
Angeles.

McDowell, A.G.

1990 Furisdiction in the Workmen's Community of Deir el-Medina (Egyptologische Uitgaven 5).

Mahmoud Abd el-QAder, A.

2011 Catalogue of Funerary Objects from the Tomb of the Servant in the Place of Truth Sennedjem

Molinero Polo, M.Á.

2000 "Meretseguer", en: J. Alvar (ed.): Diccionario de mitología universal, Madrid: 599
PiAnKoff, A.

1954 The tomb of Ramesses VI. Texts (Bollingen Se ries $\mathrm{XL}_{1}$ ). New York.

Picci, D.

2006 "La dea Mertseger sul cofanetto portaushabti KS 1969", en: S. Pernigotti y M.
Zecchi (eds.): Il coccodrillo eil cobra. Aspetti dell'universo religioso egiziano nel Fayyum e altrove. Atti del colloquio Bologna-20/21. Aprile 2005, Imola: 179-193.

Piccione, P.A.

1990 "Mehen, Mysteries, and Resurrection from the Coiled Serpent", FARCE 27: 43 -

PirelLi, R.

2000 "Sarcófago de Sepi" en: F. Tiradritti (ed.) Tesoros egipcios de la colección del Museo de El Cairo, Barcelona: 126-127.

Porter, B.; Moss, R.L.B.

1970 Topographical Bibliography of Ancient Eoyptian Hieroglyphic Texts, Reliefs and Paintings. Volume I, the Theban Necropolis. Part ${ }_{1}$ Private Tombs. Oxford, 2nd edition.

1973 Topographical Bibliography of Ancient Eoyptian Hieroglyphic Texts, Reliefs and Paintings. Volume I, the Theban Necropolis. Part 2, Royal Tombs and Smaller Cemeteries. Oxford, 2nd edition.

QUIRKE, S.

2003 La religión del Antiguo Egipto. Madrid.

REEMES, D.M.

2015 The Egyptian Ouroboros: An Iconological and Theological Study. University of California. Los Angeles.

SADEK, A.I.

1987 Popular Religion in Egypt during the New Kinodom Hildesheimer Äsyptologische Beiträge 27). Hildesheim.
SALES, J.C.

2012 "O caso Paneb (Papiro Salt 124). Entre a frustação e o senso de justiça", Cultura. Re vista de História

2006 La tomba de Sennedjem a Deir el-Medina TT Tesis doctoral. Universitat de Barcelona.

SHAW, I.; Nicholson, P.T.

1995 British Museum Dictionary of Ancient Egypt. London.

Tosi, M.; Nicola, M.T.; Bierbrier, M.L.

2003 "Deir el Medina, la carriera del capo operaio Paneb. Un riesame", REAC 5: 91-98.

Tosi, M.; Roccati, A.

1972 Stele e altre epigrafi di Deir el Medina: $n$. $50001-n .50262$. Torino.

Valbelle, D

1976 "Meresger", en: W. Helck y O. Eberhard (eds.): $L \ddot{A}$ IV, Wiesbaden: 79-80.

Vernus, P.

2003 Affairs and Scandals in Ancient Egypt.

VERnUS, P.; YoyotTe, J.

Besticire des Pharaons. Paris. 


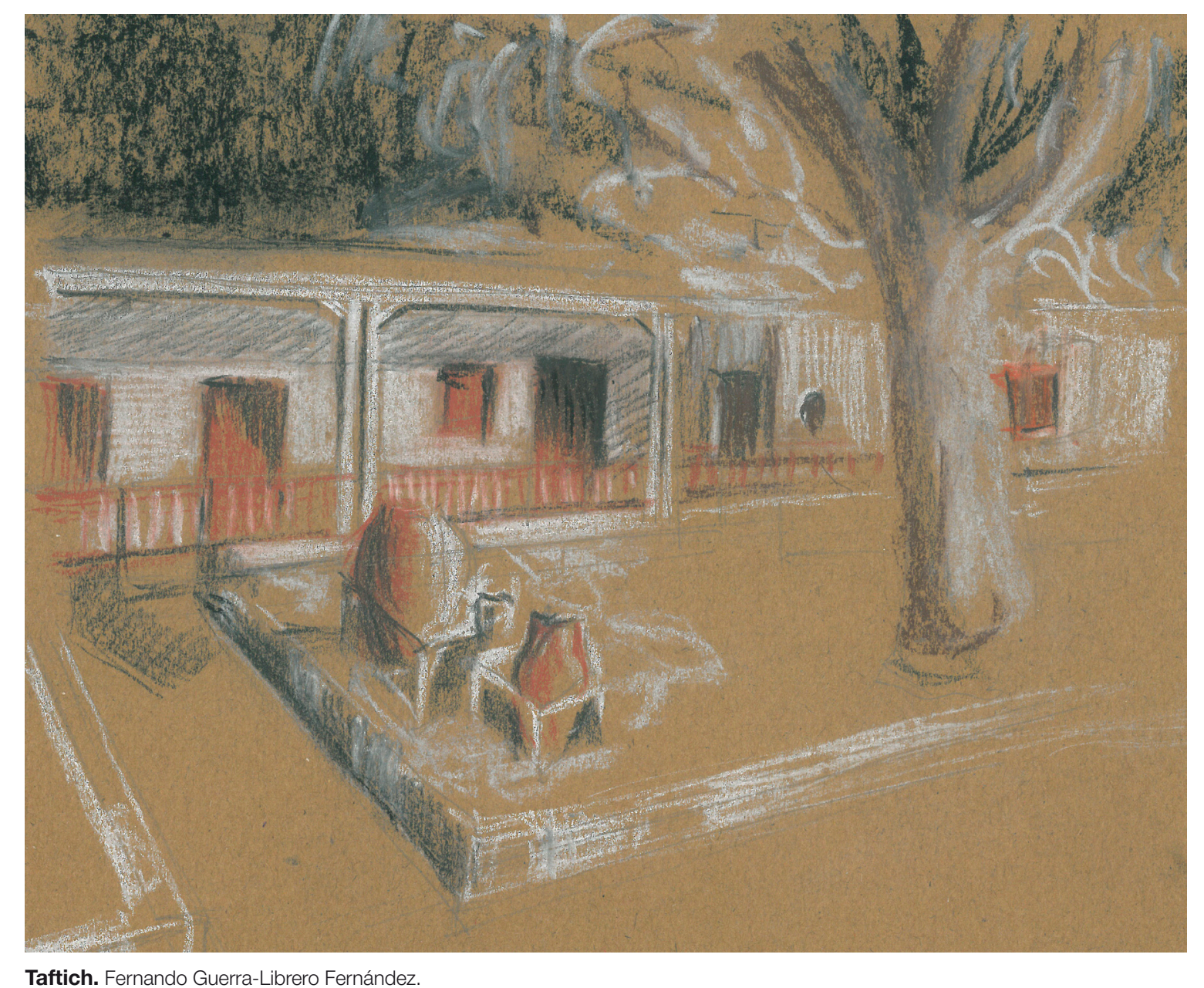

Taftich. Fernando Guerra-Librero Fernández. 


\section{Índice | Contents}

Trabajos de Egiptología está producida por

de la Universidad de La Laguna

$\mathrm{C} /$ Blanco $1,2^{\circ}$

38400 Puerto de la Cruz

España

( De los textos: sus autores y Trabajos de Egiptología

Diseño de arte y maquetación

Amparo Errandonea

Imprime: Gráfica Los Majuelos

Depósito Legal: TF 935-2015
José Miguel BARRIOS MUFREGE Covadonga en la Caldera del Teide 5

Foreword

Carta a una hermana en la luz / Letter to an enlightened sister 11

Estudio preliminar de la cerámica procedente de las excavaciones en la $\Pi \pi$ 209, Luxor,

Egipto

ZUlema BARAHONA MENDIETA

Amparo ERRANDONEA Liebestod 31

La ocupación macedónica y la Dinastía Lágida. Impacto político, económico y social Francisco BOSCH PUCHE

$$
\text { Cristina GIL PANEQUE Et il pleut sur Bruxelles } 75
$$

Reflexiones sobre Meretseguer en la estela EA272 del British Museum

Elisa CASTEL RONDA

Fernando GUERRA-LIBRERO FERNÁNDEZ Taftich 93

Ramesses III as Guarantor of Maat: the Iconographic Evidence at Medinet Habu Salvador COSTA, Teresa MAGADÁN

Fernando GUERRA-LIBRERO FERNÁNDEZ Muro de la casa de excavación 115

Iconographic Rendering of the Notion of Purification in Two Elements Included in the Vignettes of Chapters 17 and 125 of the Book of the Dead

ucía DÍAZ-IGLESIAS LLANOS

$$
\text { Isabel SÁNCHEZ MARQUÉS Adoratriz del Dios } 163
$$

Taboo - bwt?

Paul John FRANDSEN

Fernando GUERRA-LIBRERO FERNÁNDEZ Barco en el Nilo 193

Flat-Section Hairpins during the Egyptian Predynastic Period? A Proposa

$$
\text { of Identification and Typology }
$$

Candelaria MARTÍN DEL RÍO ÁLVAREZ

Isabel SÁNCHEZ MARQUÉS Plañidera 211 
José Miguel BARRIOS MUFREGE Covandonga en el patio de la TT 209, excavando el depósito de momificación 243

\section{The Courtyard of TT 209 (Areas C1 and C2). Seasons 2012 to 2014}

Miguel Ángel MOLINERO POLO, Cristo Manuel HERNÁNDEZ GÓMEZ

Hassan MOHAMED ALI, Saad BAKHIT ABD EL HAFEZ

Daniel Miguel MÉNDEZ RODRíGUEZ, Fernando GUERRA-LIBRERO FERNÁNDEZ,

Carlos GARCÍA ÁVILA, Lucía DíAZ-IGLESIAS LLANOS,

Zulema BARAHONA MENDIETA, José Miguel BARRIOS MUFREGE,

Paloma COLL TABANERA

Isabel SÁNCHEZ MARQUÉS Papiros 271

Algunas reflexiones sobre Uluburun y el intercambio comercial y cultural

en el Mediterráneo Oriental

Antonio PÉREZ LARGACHA

Fernando GUERRA-LIBRERO FERNÁNDEZ Hotel Sheherazade 289

The Framework of the Meeting. Narrative Uses of Stelae in Egyptian Literary Texts José Ramón PÉREZ-ACCINO

Sacha GÓMEZ MOÑIVAS En recuerdo de Covadonga 301

\section{Introducción a la investigación arqueológica para estudiantes}

a través de reconstrucciones virtuales

Sofía PÉREZ-RUIZ, Ainara ACEBO, Pilar RODRÍGUEZ MARÍN, Sacha GÓMEZ MOÑIVAS

Isabel SÁNCHEZ MARQUÉS Out of the blue 311

Lucernas decoradas con la imagen de una rana del yacimiento de Oxirrinco,

El-Bahnasa, Egipto

Esther PONS MELLADO

Submission guidelines
245

A Covadonga le gustaba conducir, le apasionaba estar al volante de su coche. "Pareces una chica A del futurismo italiano", le decía un amigo, aunque su primer automóvil fuera pequeño, blanco con un techo amarillo y a veces le costase llegar a su destino. Estuvimos años riendo cuando nos acordábamos del nombre con que habíamos bautizado aquella máquina. En nuestro recuerdo, ella sigue siendo la joven radiante y activa que conocimos a sus veinte años. Y su personalidad permanece entre nosotros como un perfume indeleble, retomando los versos del poeta alejandrino que tanto le gustaba. Quienes asistieron a sus conferencias conocieron la calidez de su voz; sus clases en la universidad crearon vocaciones; son, sin embargo, los que compartieron con ella su amistad quienes disfrutaron de los rasgos más sobresalientes de su personalidad: la generosidad, la entrega desinteresada a los demás. Cova tenía una capacidad excepcional para la empatía hacia los que se le acercaban. Fso le hizo ganar afectos en todos los ámbitos de su vida y conservarlos, desde los compros des tributo proser. Este y la huella que dejó en su generación.

Un grupo de amigos que vivimos con ella sus labores de docencia, investigación o proyectos arqueológicos, decidimos rendirle un homenaje particular, uno más entre los que se le han dedicado desde el momento en que su $k a$ voló al cielo. Este volumen es el resultado de esa voluntad de crear nuestro monumento a su memoria, por tantas experiencias inolvidables compartidas. El homenaje ha querido ser un caleidoscopio de miradas desde las que reflejar la personalidad de Covadonga y hemos preferido romper el formato académico tradicional. Los artículos se entrelazan con fotografías, dibujos, semblanzas o poemas que pretenden dejar constancia de la huella que ella legó a sus autores. Es nuestra ofrenda para que su $b a$ siga regresando desde donde esté hasta nosotros, cada vez que la nombremos y en cada ocasión en que su recuerdo tome forma en nuestro corazón. 


\section{Foreword}

Covadonga enjoyed driving; she loved being behind the wheel of her car. A Uriend used to tell her "you look like a woman of the Italian Futurism," although her first car was small and white with a yellow roof, and sometimes had difficulties reaching its destination. We laughed for years remembering the name with which we baptized that machine. In our memories, she is still the radiant and active young woman we met in her twenties, and her personality remains among us as an indelible scent, to draw upon the verse of an Alexandrian poet that she loved so much. Those who attended her lectures knew the warmth of her voice, her classes at the university created vocations, however, it is those who shared her friendship who enjoyed the most outstanding features of her personality: generosity, and selfless dedication to others. Cova had an exceptional capacity for empathy toward those who approached her This allowed her to win affection in all aspects of herfe and to retain it, from the classmates of her early schooldays, to the a circles of all a the generations as the legacy of an exceptional individual, and the mark she left on her generation.

As a group of friends who lived with her through teaching, research, or archaeological projects, we have decided to pay her a particular tribute; one more among the many that have been dedicated to her from the moment her ka flew to heaven. This volume is the result of our desire to create for her a monument to so many unforgettable shared experiences. We decided that this tribute should be a kaleidoscope, to reflect Covadonga's personality, and we have thus preferred to break from the traditional academic format. The articles are intertwined with photographs, drawings, sketches, or poems that are intended to record the traces she left with their authors. It is our offering so that her ba keeps coming back to us from where she now is, every time that her memory takes shape in our hearts.

\section{Carta a una hermana en la luz} SON le habla a su padre, como la hija que le habla a su madre.

¡O Senet, Senet Meret! Que Osiris-Khentamentiu te otorgue millones de años respirando aliento en tu nariz, dándote pan y cerveza junto a Hathor, Señora de la Tierra de Luz.

Tu condición es como la vida millones de veces, por orden de los dioses que están en el cielo y la en tierra. Que Ha, Señor de Occidente, actúe en tu favor de acuerdo a sus deseos, que Anubis, Señor del Buen Entierro actúe para ti como él lo quiera. Que pueda levantar una barrera contra los enemigos, hombres y mujeres malvados que se oponen a tu casa, tus hermanos, tus padres, tu memoria y tus hombres
obras.

Fuiste excelente en la tierra, por lo que también serás capaz y eficiente en el Más Allá. Que se te hagan ofrendas, que se realice la fiesta Haker para ti, que hagan la fiesta del Wag, que te den pan y cerveza del altar de Khentamentiu. Que puedas viajar río abajo en la Barca del Ocaso y que navegues río arriba en la Barca de la Mañana. Que estés justificada junto a cada dios. Que te conviertas en río arriba en la Barca de la Mañana. Que estés justificada junto a
alguien elogiado por nuestros espíritus masculinos y femeninos.

¿Has visto estos lamentos ahora que estás allí en el Más Allá?

Oh, gran dolor! Útil es una queja para hablar de lo que se hace contra nosotros de una manera tan injusta. Aunque no hay nada que hayamos hecho contra los dioses, y aunque no hemos comido de sus ofrendas, jsin embargo nos han privado de ti

Te han traído aquí a la Ciudad de la Eternidad, sin que albergues ira contra nosotros. Pero si hubiera un reproche en tu corazón, olvídalo por el bien de tus hermanas y hermanos. Sé misericordiosa, sé misericordiosa, y así todos los dioses del nomo de This serán misericordiosos contigo.

Mantén alejadas todas las aflicciones dirigidas a nosotros, tus hermanas y hermanos, porque tú sabes que tenemos una gran necesidad de esto. Que vivas para nosotros y así el Grande te elogie. Que la cara del gran dios sea gozosa para ti, y que él te dé pan puro con ambas manos.

Todos los sacrificios funerarios se han realizado para la que está en la luz, a fin de que pueda interceder por nosotros, los sobrevivientes en la tierra que han quedado atrás. Por lo tanto, busca que el que causó aquello de lo que estamos sufriendo ahora te dé una explicación, porque necesitamos entender y queremos también ser justificados delante de los dioses como lo eres ahora, entendiendo todo, justificada y transfigurada.

Son los hermanos y hermanas quienes le hablan a su hermana, para quien la luz ya nunca se oscurecerá. 


\section{Letter to an enlightened sister}

is the brothers and sisters who are speaking to their sister like the son who is speaking to
his father, like the daughter who is speaking to her mother.

O Senet, Senet Meret! May Osiris-Khentamentiu make millions of years for you by breathing breath into your nose, by giving bread and beer beside Hathor, Lady of the Land-of-Light.

Your condition is like life millions of time, by command of the gods who are in heaven and earth May $\mathrm{Ha}$, Lord of the West, act on your behalf as he wishes, may Anubis, Lord of the Good Burial act for you as he wishes. May you erect a barrier against male and female enemies, male and female evil ones who oppose your house, your brother, your mother, your memory, your deeds.

You are one who was excellent on earth, therefore you will also be capable in the hereafter. May one make offerings to you, may one make the Haker-feast for you, may one make the Wag-feast for you, may one give you bread and beer from the altar of Khentamentiu. You will travel downstream in the Bark-of-the-Evening and sail upstream in the Bark-of-the-Morning. May you be given justification at the side of every god. Make yourself into someone praised by our male and female ghosts.

Have you seen this lamentation now that you are there in the hereafter?

$\mathrm{O}$, great grief! Useful is a complaint to speaking concerning this which is done against us in such an unjust way, although there is nothing that we have done against the gods, and although we have not eaten of his offerings, nevertheless they have deprived us of you!

You have been brought here to the City of Eternity, without you harbouring anger against us. But if there is a reproach in your heart, forget it for the sake of your sisters and brothers. Be merciful, be merciful, then all the gods of the Thinite nome will be merciful towards you.

Keep away all afflictions directed at us, your sisters and brothers, for you know we have a need for this. May you live for us in order for the Great One to praise you. May the face of the great god be joyous because of you, so that he will give you pure bread with both his hands.

All mortuary sacrifices are made for the enlightened one in order to intercede on behalf of the inhabitants of earth. Therefore seek an explanation from him who caused that of which we are suffering now, for we want to be justified in front of the gods same as you are now.

It is the brothers and sisters who are speaking to their sister, she for whom the light will never darken. 